\title{
DESIGN DE UM JOGO DIDÁTICO PARA O ENSINO DE CONCEITOS DE GENÉTICA HUMANA
}

\author{
Maria Guadalupe Couto do Canto1; Aline Grohe Schirmer Pigatto²
}

\section{RESUMO}

O ensino da Genética é considerado, por vezes, muito complexo pela forma tradicional como é desenvolvido. Pensando nisso, este trabalho pretende abordar como o lúdico pode contribuir no processo de ensino e de aprendizagem da Genética para estudantes do ensino básico, de maneira diferente e que possibilite aprender e construir conceitos. Assim, o presente trabalho tem como objetivo relatar o processo de design de um jogo didático que propõe trabalhar de forma inovadora conceitos de Genética, além disso, apresenta o processo de planejamento e criação do recurso. O jogo intitulado Jogo da Roleta de Mendel foi construído no microsof Power Point, contém uma sequência de atividades em que o estudante precisa fazer escolhas a partir da compreensão de conceitos de genética. $O$ jogo é uma sugestão de atividade que envolve a $1^{\underline{a}}$ e $2^{\underline{a}}$ Lei de Mendel e que busca ser uma efetiva contribuição para o aprendizado de Genética.

Palavras-chave: Leis de Mendel; Lúdico; Ensino-aprendizagem.

Eixo Temático: Educação, Cultura e Comunicação.

\section{INTRODUÇÃO}

A Genética é responsável pelo estudo do material genético (o DNA) e de seus padrões hereditários. Tem um grande impacto na sociedade, pois está inserida no contexto tecnológico com vários avanços e inovações científicas na área de Biologia Molecular, sobretudo, relacionadas com a área da saúde e da agricultura (SNUSTAD; SIMMONS, 2013). Compreender essa ciência é essencial para entender os mecanismos de transmissão hereditária e também para o desenvolvimento do senso crítico diante dessas inovações científicas, além disso, é fundamental o acesso à ciência pela população, tanto na perspectiva cultural, quanto social (LOPES, 2004).

\footnotetext{
${ }^{1}$ Maria Guadalupe Couto do Canto- UFN. lupe canto@hotmail.com

${ }^{2}$ Aline Grohe Schirmer Pigatto - UFN. agspigatto@gmail.com
} 
Por envolver uma rede de conceitos, a Genética é considerada muito complexa, porém o estudante precisa consolidar esses conceitos para construir significativamente seus conhecimentos. Silveira (2008) explica que ter conhecimento do conceito, é um fator decisivo para o estudante, na tarefa de resolver um problema. E é tarefa do professor, identificar fragilidades na construção de conceitos de Genética, a partir das suas ideias prévias, assim como desenvolver estratégias e oportunidades de aprendizagem que contribuam com a construção do conhecimento biológico.

Quando se fala em Genética em sala de aula, uma das principais dificuldades dos alunos, nas aulas de Biologia, está relacionada justamente à compreensão conceitual. Vários foram os avanços no campo da Genética, e as pesquisas mostram que essa é uma área de difícil compreensão para o Ensino de Biologia, em virtude da complexidade dos fenômenos à que concerne e à discussão sobre sua construção conceitual e abstração de conceitos. Porém, fica difícil identificar erros conceituais pelo professor, a partir da avaliação de textos ou esquemas elaborados pelos alunos, nos quais apenas repetem o que leram nos livros ou ouviram do professor. Soares, Pinto e Rocha (2005) explicam que o aluno pode repetir corretamente, mas ter assimiliado os conceitos de forma errada.

Não obstante a importância da Genética, a experiência com estudantes tem mostrado que o ensino dessa ciência conta com alguns obstáculos, entre eles, a falta de recursos, ambiente adequado, pouca carga horária, presença de cálculos matemáticos e o interesse do próprio aluno (SOUSA et al., 2016; ARAÚJO et al., 2018). Além disso, os esquemas dos livros didáticos, na maioria das vezes, não esclarecem devidamente questões conceituais e, as queixas dos estudantes se resumem na gama de conceitos e na falta de metodologias que oportunizem uma aprendizagem acessível e estimuladora.

A utilização de jogos didáticos tem se mostrado como uma das estratégias metodológicas mais utilizadas nos últimos tempos, para o ensino e aprendizagem de Genética e, aparece com grande relevância na literatura (RAMALHO et al., 2006; GUIMARÃES et al., 2008). Em sua maioria, esses trabalhos trazem as dificuldades encontradas no ensino dessa área da Biologia as quais permeiam entre a extensa 
terminologia e o elevado grau de abstração, o que leva aos alunos optarem por decorar os conceitos e termos ao invés de compreende-los (TEMP, 2011).

Considerando que a utilização de um método dinâmico pode facilitar a aquisição e domínio do conhecimento do conteúdo de forma a contextualizarem e relacionarem a sua vida cotidiana, o recurso lúdico é um instrumento que possibilita apresentar, de forma dinâmica, o conhecimento científico de forma que ocorra aprendizagem em qualquer área de ensino (HUIZINGA, 2004).

A proposição de um jogo didático justifica-se pela atração e pela conexão que os estudantes tem com as tecnologias. Dessa forma, unindo conhecimento e diversão, este trabalho tem por objetivo, apresentar/ relatar o design de um jogo didático para abordar o estudo de conceitos de Genética, bem como o processo de planejamento e criação do recurso.

\subsection{JOGOS NO ENSINO}

O jogo didático proporciona determinadas aprendizagens e se diferencia do material pedagógico, por conter o aspecto lúdico. Segundo Moreira e Schwartz (2009), o lúdico quando introduzido na área da educação, pode ser um poderoso aliado ao ensino formal, uma vez que desenvolve a competitividade, o lado artístico, a expressividade e a descoberta de várias outras habilidades que os alunos possam ter. E, segundo Krasilchik (2004), os jogos didáticos são formas simples de simulação, cuja função é ajudar a memorizar fatos e conceitos. Além disso, é um excelente recurso para se utilizar na aprendizagem dos alunos, pois permite que assimilem de forma descontraída e prazerosa os conteúdos propostos.

$\mathrm{Na}$ educação, o jogo está relacionado a duas funções: a lúdica, que garante que o jogo proporcione diversão, o prazer (inclusive o desprazer) quando se escolhe voluntariamente, e a educativa, que proporciona a aprendizagem de qualquer coisa que agregue ao saber, aos conhecimentos do indivíduo. Para esse autor, ambas as funções devem estar equilibradas de modo que não haja somente jogo, ou apenas ensino, e ainda, explica que há duas variantes no emprego de jogos: o jogo didático, dedicado exclusivamente à aquisição de conteúdos e, o jogo educativo, que envolve ações ativas das crianças, sendo mais dinâmico e menos limitador. 
EDUCAÇÃO, SAÚDE

ETECNOLOGIA

26 A 28 DE OUTUBRO DE 2021

Conforme Fortuna (2000) e Miranda (2001), os jogos vão além do ensinar de forma divertida "sem que o aluno se dê conta". Para ele, os jogos desenvolvem importantes aspectos cognitivos como a imaginação e o raciocínio.

\subsection{JOGOS E TECNOLOGIAS}

Várias são as alternativas propostas, que podem oportunizar aos alunos 0 domínio dos conteúdos de Genética, com o lúdico: dominó, cartas, jogos de tabuleiros, jogo da memória e ainda os jogos on-line. Porém, considerando que a tecnologia, hoje, é indispensável no cotidiano e na vida da maioria das pessoas e, os jovens detém a tecnologia em suas mãos, a escola deve levar em conta essa realidade e promover a utilização de recursos digitais além de colocar ferramentas exixtentes a serviço do ensino (ALTHAUS, 2015).

Rezende (2002, p.1), alega que "não é mais uma questão de nos perguntarmos se devemos ou não inserir as novas tecnologias da informação e da comunicação no processo educativo". Profere que, "professores de várias áreas, reconhecem que, se a educação e a escola não abrirem espaço para essas novas linguagens, elas poderão ter seus espaços definitivamente comprometidos".

No entanto, existe uma alerta para a utilização de recursos tecnológicos. Há uma necessidade de que seja feita de maneira conciente e planejada, pois, por si só, não possibilitam o processo educacional. Muitos são os recursos tecnológicos, que permitem aos estudantes experimentar variadas situações, mas conforme Giraffa (2010), o que se sobrepõe à discussão de qual recurso a utilizar é, qual recurso melhor se adapta aos objetivos pedagógicos que o docente possui. "Um professor comprometido, que luta para transformar suas aulas em ambientes que promova 0 desenvolvimento do aluno, tem a sua disposição uma gama de jogos, basta saber como utilizá-los (GONÇALVES, 2010, p.2).

No entanto, o maior desafio é fazer com que tais tecnologias cheguem à sala de aula, que façam parte do dia a dia dos alunos, professores e ambiente escolar e dessa forma, associe o ensino tradicional com os jogos lúdicos beneficiando 0 processo de aprendizado (HUIZINGA, 2004). 


\section{METODOLOGIA}

Este estudo refere-se a um relato de experiência, que segundo Lopes (2012, p. 1),

[...] pertence ao domínio social, fazendo parte das experiências humanas, devendo conter tanto impressões observadas quanto conjecturadas. Este tipo de estudo é importante para a descrição de uma vivência particular que suscitou reflexões novas sobre um fenômeno específico.

No caso deste relato, faremos a descrição do processo de planejamento e da elaboração de um jogo didático.

\section{RESULTADOS E DISCUSSÕES}

O jogo foi elaborado baseado na literatura existente sobre conteúdos específicos de genética e serve como atividade para a compreensão, aprendizado e fixação desses conteúdos. Para a sua elaboração, utilizamos o software Power Point, pois nos permite criar jogos usando modelos do próprio Power Point, utilizando texto, imagens, música e animações, além de fazer slides que possibilitam a apresentação e realização do jogo.

O jogo foi denominado JOGO DA ROLETA DE MENDEL e inicia com um slide contendo genótipos e fenótipos das características: tipo de cabelo, cor de cabelo, forma do olho e cor do olho. Os estudantes devem seguir passos prédeterminados para a realização de cada uma das etapas do jogo. Esses passos são, inicialmente, a escolha de características humanas. Na figura 1 é mostrado o primeiro slide do jogo exemplificando as características utilizadas.

Figura 1 - Primeiro slide do jogo no qual são mostradas as características que serão trabalhadas.

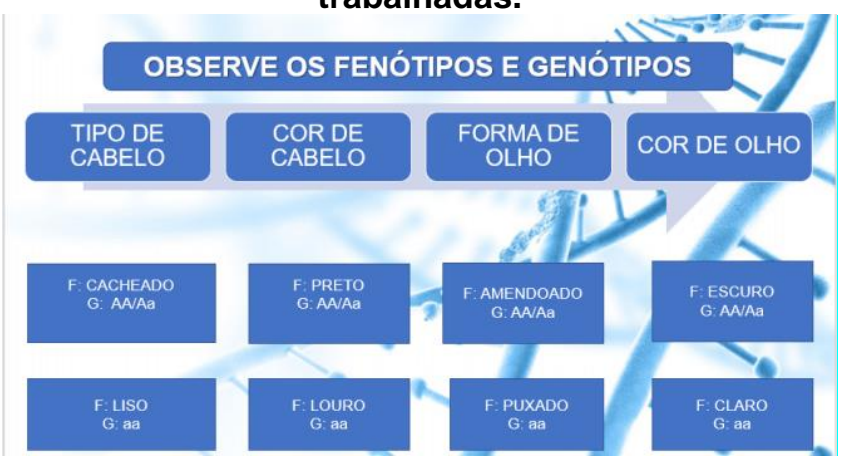

Fonte: elaborado pelas autoras. 
Conforme a figura 1, já no primeiro slide do jogo os estudantes terão contado com as características que serão trabalhadas. Ao abrirem o slide eles deverão observar os fenótipos e genótipos de cada uma das características elencadas, quais sejam: tipo de cabelo, cor de cabelo, forma do olho e cor do olho.

Figura 2 - Segundo slide do jogo no qual são mostradas os fenótipos possíveis em relação ao tipo e cor de cabelo.
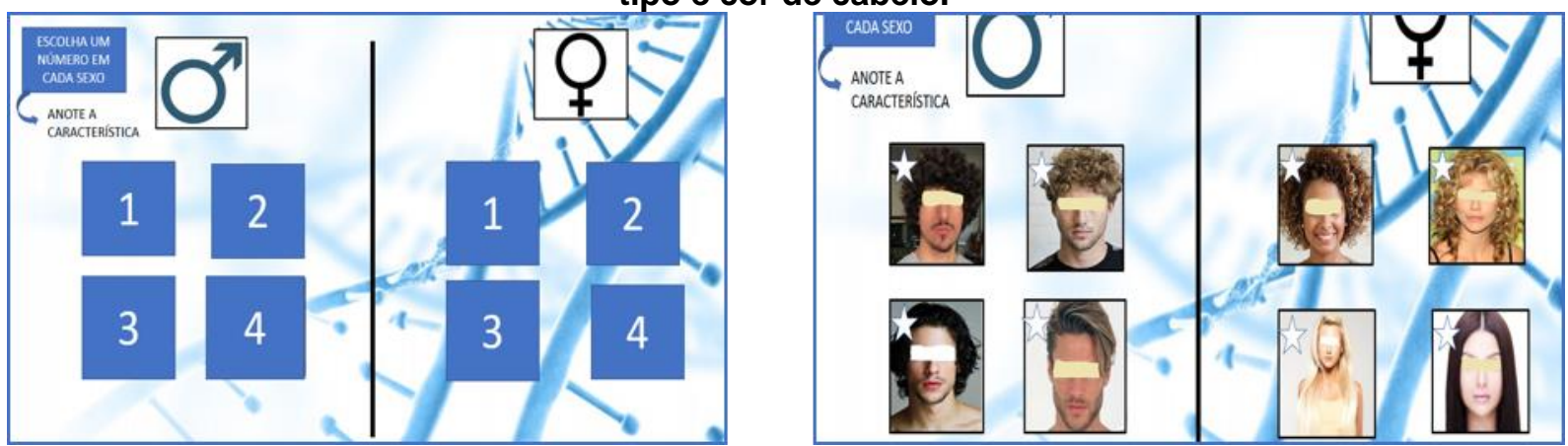

Fonte: elaborado pelas autoras.

Conforme a figura 2, no segundo slide do jogo os estudantes visualizarão as características fenotípicas possíveis de serem trabalhadas. Ao abrirem as janelas, eles deverão observar os fenótipos de cada uma das características elencadas, conforme o tipo de cabelo e a cor de cabelo e escolher um número para cada um dos sexos. Em seguida, anotar os fenótipos sugeridos nas figuras disponibilizadas.

Figura 3 - Terceiro slide do jogo no qual são mostradas os fenótipos possíveis em relação ao tipo e cor de olho.
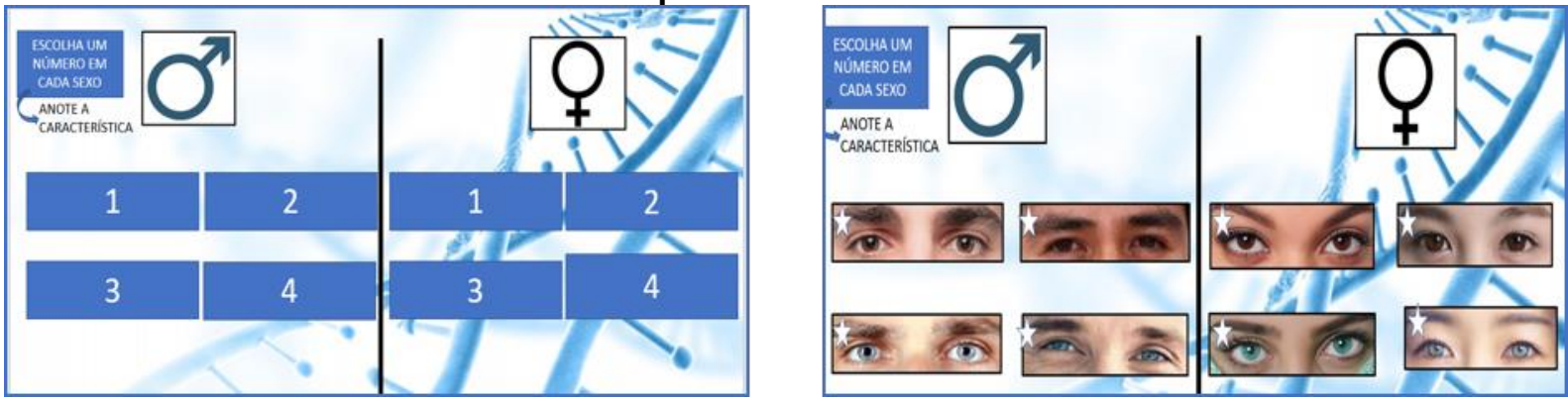

Fonte: elaborado pelas autoras.

Conforme a figura 3, no terceiro slide do jogo, ao abrirem as janelas, os estudantes deverão observar os fenótipos de cada uma das características elencadas, conforme o tipo e a cor de olhos e escolher um número para cada um dos sexos. Em seguida, anotar os fenótipos sugeridos nas fotografias. 
Figura 4 - Quarto slide do jogo no qual consta uma roleta contendo os possíveis genótipos para trabalhar as características elencadas.

Fonte: elaborado pelas autoras.

\section{ROLETA DOS GENÓTIPOS}

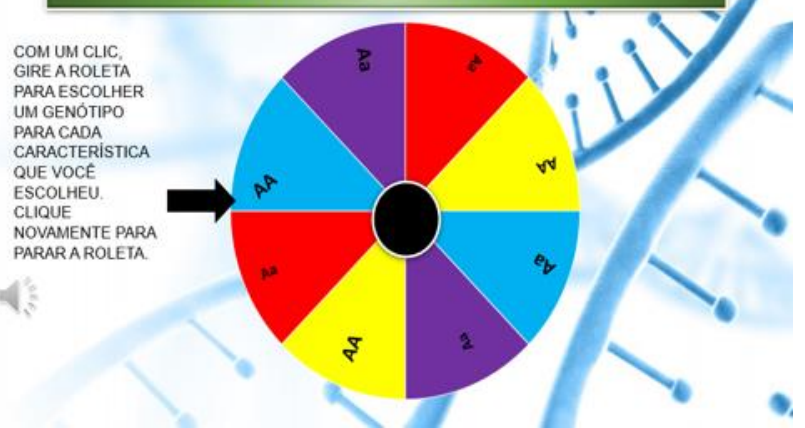

Conforme a figura 4, no quarto slide do jogo, ao clicar na roleta, ela gira e ao clicar novamente ela para com a seta em um dos quadrantes, contendo um tipo de genótipo. Dessa forma, o estudante escolhe o genótipo correspondente as características sugeridas nas fotografias. (Para a característica recessiva não será necessário rodar a roleta). Em seguida, anotar os genótipos sorteados pela roleta.

Exemplo: Ao girar a roleta para a característica "mulher olho amendoado", a roleta parou no genótipo "Aa". Para a característica "homem olho puxado" não é necessário girar a roleta, pois trata-se de uma característica recessiva, com um único genótipo, o "aa". Ao realizar o cruzamento, o estudante usará os genótipos "Aa $\mathrm{X}$ aa" para obter os resultados possíveis.

Ao obter a filiação, os estudantes deverão escolher, em cada um dos cruzamentos, um único indivíduo para representar, e em seguida, escolher no banco de imagens disponibilizado no jogo, as figuras correspondentes e montar o indivíduo obtido com os cruzamentos, por exemplo: mulher, cabelo crespo e escuro; olho azul e amendoado.

Figura 5 - Figura contendo as características fenotípicas resultantes do cruzamento obtido no exemplo. 


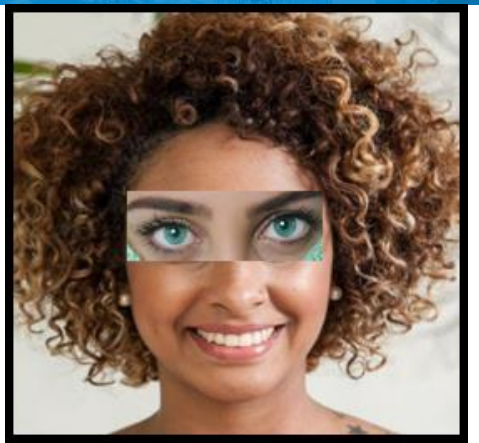

Fonte: elaborado pelas autoras.

Ao chegarem nesta etapa, os estudantes passam de fase, então novos conceitos devem ser inseridos para que possam resolver as próximas questões.

Segundo Baiotto, Sepel e Loreto (2016), características como a cor dos olhos, a inserção do lóbulo da orelha, a cor da pele e a capacidade de enrolar a língua são características humanas comumente utilizadas como exemplos de herança mendeliana simples, monogênica, que é determinada por um único gene. Porém, trata-se, de características de herança poligênica ou multifatorial, onde a herança é determinada por vários genes e diversos fatores ambientais.

Didaticamente, utilizamos primeiramente como exemplo de característica monogênica, a cor dos olhos, forma do lóbulo da orelha, cor da pele, etc., para facilitar o entendimento, uma vez que traz características extremas e visíveis (alelo para cor azul recessivo e para cor castanha, dominante). Porém, após este entendimento, o aluno passa a compreender que, a existência de uma gama maior de colorações se deve ao fato de que é uma determinação poligênica (vários genes atuam para a mesma característica) (BAIOTTO; SEPEL; LORETO, 2016).

Figura 6 - Décimo slide do jogo no qual são mostradas as características que serão trabalhadas.

\section{OBSERVE A COR DOS OLHOS}
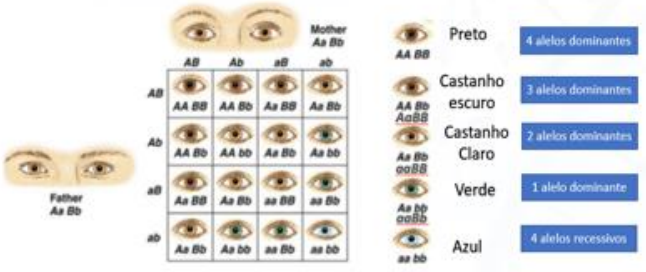

Fonte: elaborado pelas autoras. 
Conforme a figura 6, no décimo slide do jogo os estudantes terão contado com os diferentes genes que determinam a cor de olhos: gene "A" e gene "B". Além dos possíveis genótipos e fenótipos para essa característica.

Figura 7 - Décimo primeiro slide do jogo no qual são mostradas os possíveis fenótipos da característica cor de olho.
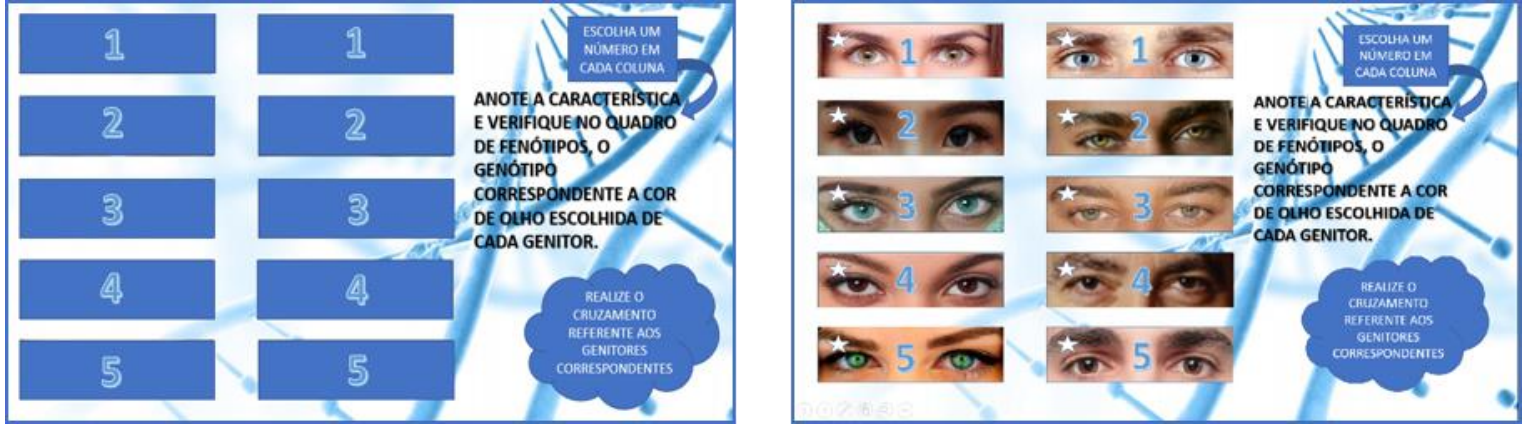

Fonte: elaborado pelas autoras.

Conforme a figura 7, os estudantes deverão escolher os fenótipos disponibilizados no slide 11 do jogo, anotar os possíveis genitores a fim de realizar cruzamentos.

Figura 8 - Décimo segundo slide do jogo no qual consta uma roleta contendo os possíveis genótipos para trabalhar as características poligênicas.

Fonte: elaborado pelas autoras.

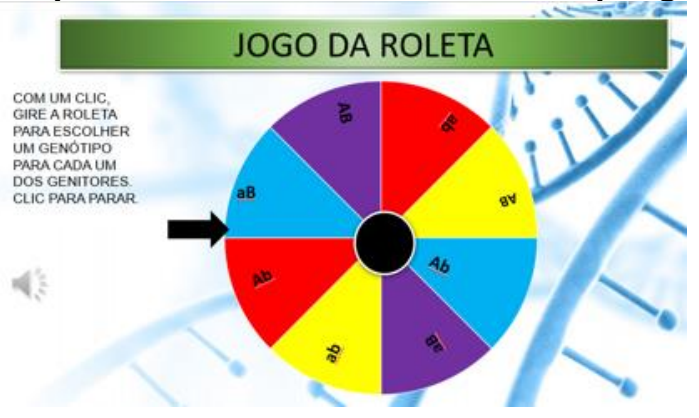

Conforme a figura 8, no décimo segundo slide do jogo, os estudantes giram a roleta para obter os genótipos dos genitores. Agora serão duas duplas de alelos para cada genitor, por exemplo: $a B+a b=a a B b ; A B+A B=A A B B$. Neste exemplo, os genótipos a serem cruzados são: aaBb $X$ AABB, resultado, do cruzamento. Então os estudantes deverão repetir os mesmos procedimentos descritos acima, para montarem suas figuras conforme os resultados dos cruzamentos. 


\section{CONCLUSÃO}

Conforme o objetivo proposto, neste trabalho relatamos o planejamento e 0 design de um jogo que busca qualificar o processo de aprendizagem de conceitos de Genética, de modo especial, no que se refere aos conteúdos relacionados às Leis de Mendel.

Geralmente, os conceitos de genética são considerados de difícil entendimento e por isso vimos a necessidade de utilizar uma estratégia diferenciada a fim de estabelecer uma relação entre os conteúdos teóricos e a prática. O jogo didático possibilita, de forma lúdica e dinâmica, a compreensão, o aprendizado e a assimilação dos conteúdos abordados nas aulas teóricas de genética.

Com tanta tecnologia a mercê das pessoas na atualidade, fica difícil mobilizar os estudantes para os saberes utilizando apenas as metodologias tradicionais. Grande parte dos alunos tendem a reclamar de que as aulas são cansativas e pouco atrativas com a utilização apenas do livro didático.

A falta de mobilização dos alunos perante os conteúdos, por vezes nos leva a refletir sobre nossas atividades. Esperamos que este jogo possa contribuir não apenas no ensino aprendizagem mas, também, promover o divertimento aumentando a interação a aparticipação dos alunos nas aulas, pois o ensino da genética com atividades práticas e lúdicas, é suporte que complementa os conceitos teóricos.

\section{AGRADECIMENTOS}

O presente trabalho foi realizado com apoio da Coordenação de Aperfeiçoamento de Pessoal de Nível Superior - Brasil (CAPES) - Código de Financiamento 001.

\section{REFERÊNCIAS}

ALTHAUS, N. Os jogos online como ferramentas na resolução de problemas com o uso de tecnologias digitais. 2015. Dissertação (Mestrado profissional em Ensino de Ciências Exatas) - Programa de Pós-graduação em Ensino de Ciências Exatas, Centro Universitário UNIVATES, Lageado, 2015. 
ARAÚJO, M. S.; FREITAS, W. L. S.; LIMA, S. M. S.; LIMA, M. M. O. A genética no contexto de sala de aula: dificuldades e desafios em uma escola pública de Floriano - PI. Revista Ensino de Ciências e Matemática, v. 9, n. 1, p. 19-30, 2018.

BAIOTTO, C. R.; SEPEL, L. M. N.; LORETO, E.L. S. Para ensinar genética mendeliana: ervilhas ou lóbulos de orelha? Genética na Escola, v. 11, n.2, p. 283296, 2016.

FORTUNA, T. R. Sala de aula é lugar de brincar? In: XAVIER, M.L.F.; DALLA ZEN, M.I.H. Planejamento: análises menos convencionais. Porto Alegre: Mediação, 2000. p. $147-164$.

GIRAFFA, Lúcia M. M. Vamos bloggar professor? Possibilidades, desafios e requisitos para ensinar Matemática no século XXI. Revista de Ensino de Ciências e Matemática, v.1. n. 2, p. 97-110, 2010.

GONÇALVES, Max L. C. O uso do jogo on-line como possibilidade de aprendizagem da matemática. Novas Tecnologias na Educação, v. 8, n. 3, 2010.

GUIMARÃES, K. M. N.; OLIVEIRA, S. F.; AKIMOTO, A.; HIGARI, C.; BARBOSA, L. S.; ROCHA, D. M. S.; CORREIA, A. Combinar e recombinar com os dominós. Genética na escola, v. 3, n. 2, p. 1-7, 2008.

HUIZINGA, J. Homo ludens: o jogo como elemento da cultura. 5. ed. São Paulo: Perspectiva / EDUSP, 2004.

KRASILCHIK M. Prática de Ensino de Biologia. 4. ed., São Paulo: Editora da Universidade de São Paulo, 2004.

LOPES, M. C. A inclusão como ficção moderna. Pedagogia, v 3, n. 6, p. 7-20, 2004. LOPES, M. V. de O. Sobre estudos de casos e relatos de experiências... Revista da rede de Enfermamgem do nordeste, 2012. Editorial. Disponível em: http://www.periodicos.ufc.br/rene/article/view/4019/3159. Acesso em: 22 ago. 2021. MIRANDA, S. No fascínio do jogo, a alegria de aprender. Ciência Hoje, v. 28, n. 168, p. 64-66, 2001.

MOREIRA, J. C. C.; SCHWARTZ, G. M. Conteúdos lúdicos, expressivos e artísticos na educação formal. Educ. rev. (on line), n. 33, p. 205-220, 2009. Disponível em: https://www.scielo.br/j/er/a/7Kmsx5Qy6M45w4v6FSrNRpc/abstract/?lang=pt. Acesso em: 30 Ago. 2021. 
RAMALHO, M. A. P.; SILVA, F. B.; SILVA, G. S.; SOUZA, J. C. Ajudando a fixar os conceitos de genética. Genética na escola, v. 1, n. 2, p. 45-49, 2006.

REZENDE, Flávia. As novas tecnologias na prática pedagógica sob a perspectiva construtivista. Revista Ensaio, v. 2, n 1, mar.- 2002, p. 1 a 18. Disponível em: https://www.scielo.br/j/epec/a/qpwpgZ59xcxP9VNWNmkzc4K/?lang=pt

Acesso em 22 ago. 2021.

SILVEIRA, L. F. S. Uma contribuição para o ensino de genética. Dissertação (Mestrado em Ciências e Matemática) - Universidade Católica do Rio Grande do Sul, 2008.

SOARES, K. DA. C.; PINTO, M. da C.; ROCHA, M . de. Cada lócus por si mesmo: por onde andam esses Genes?. Genétíca na sala de aula: estratégias de ensino e aprendizagem. Rio de Janeiro: Promed/SEE/UFRJ, 2005.

SOUSA, E. S.; JUNIOR, F. H. N.; CAVALCANTE, C. A. M.; HOLANDA, D. A. S. A genética em sala de aula: uma análise das percepções e metodologias empregadas por professores das escolas públicas estaduais de Jaguaribe Ceará. Conex. Ci. e Tecnol, v. 10, n. 4, p. 16-24, 2016.

SNUSTAD, D. P.; SIMMONS, M. J. Fundamentos de genética. 6. ed. Rio de Janeiro: Guanabara Koogan, 2013.

TEMP, D. S. Facilitando a aprendizagem de genética: uso de um modelo didático e análise dos recursos presentes em livros de biologia. 2011. Dissertação (Mestrado em educação em ciências: química da vida e saúde). Universidade Federal de Santa Maria, Santa Maria, 2011. 